\title{
ESTUDO DE TOPOSSEQÜÊNCIA DA BAIXADA LITORÂNEA FLUMINENSE : EFEITOS DO MATERIAL DE ORIGEM E POSIÇÃO TOPOGRÁFICA ${ }^{(1)}$
}

\author{
M. B. SILVA(2), L. H. C. ANJ OS(3), \\ M. G. PEREIRA ${ }^{(3)}$ \& R. A. M. NASCIMENTO(3)
}

\begin{abstract}
RESUMO
A influência dos materiais de origem, rochas do Pré-Cambriano e sedimentos coluviais e aluvionares delas derivados, e da posição topográfica na gênese de solos foi estudada em uma toposseqüência representativa das feições geomorfológicas da Baixada Litorânea Fluminense (RJ), no campus da Universidade Federal Rural do Rio de J aneiro (UFRRJ ). Foram analisados seis perfis de solo, localizados no terço superior (P1 e P2), médio (P3) e inferior da encosta (P4e P5), e na baixada (P6). Os processos pedogenéticos eas características dos solos foram relacionados com as unidades geomorfológicas e litoestratigráficas descritas na região. Os perfis P1 e P2, formados 'in situ' a partir do regolito do gnaisse, têm elevada saturação por bases, textura média/argilosa e minerais primários facilmente intemperizáveis na fração areia (micas e feldspatos). 0 P3, relacionado com uma rampa de colúvio, difere dos anteriores pela elevada saturação por alumínio e ausência de minerais primários facilmente intemperizáveis. P4 e P5, também formados de colúvio, diferem do P3 pela textura superficial arenosa e presença de horizonte $E$ sobrejacente a fragi pã. 0 P6, originado de sedimentos colúvio-aluvionais, tem cores cinzentas, estrutura maciça, textura argilosa e baixa saturação por bases. Os perfis foram classificados como Argissolo (P1, P2 e P3), Planossolo (P4 e P5) e Gleissolo (P6).
\end{abstract}

Termos de indexação: Argissolos, Planossolos, drenagem do solo.

\footnotetext{
(1) Parte da Tese de Mestrado do primeiro autor, apresentada ao Departamento de Solos da Universidade Federal Rural do Rio de J aneiro - UFRRJ . Recebido para publicação em outubro de 1999 e aprovado em junho de 2001.

(2) Professora Assistente da Universidade Estadual do Maranhão - UEMA. Cidade Universitária Paulo VI, CEP 65054-970 São Luís (MA). E-mail: marlenbarros@bol.com.br

(3) Professor Adjunto do Departamento de Sol os da Universidade Federal Rural do Rio deJ aneiro- UFRRJ . BR 465, km 7, CEP 23890000 Seropédica (RJ ).E-mail: Ianjos@ufrrj.br; gervasio@ufrrj.br
} 


\title{
SUMMARY: TOPOSEQUENCE STUDY OF BAIXADA LITORÂNEA FLUMINENSE, RJ ,BRAZIL: EFFECTS OF PARENT MATERIAL AND TOPOGRAPHIC POSITION
}

\begin{abstract}
The influence of parent materials, Pre-Cambrian rocks, and colluvial and alluvial sediments derived from them, as well as their topographical position in the soil genesis were studied in a toposequence representative of the Baixada Litorânea Fluminense landscape, at the Federal Rural University of Rio de J aneiro, Brazil. Six soil profiles, located on the shoulder position (P1 and P2), backslope (P3), footsl ope (P4 and P5), and foot slope position (P6) were analyzed. The pedogenic processes and soil properties were related to the geomorphol ogic and lithostratigraphic units descri bed in the region. Profiles P1 and P2, formed in situ from the gneiss mantle, had high base saturation, medium clayey texture, and easily weathered primary minerals in the sand fraction (mica and feldspar). Profile P3, related to a thick colluvium mantle, differed from P1 and P2 due to a high aluminum saturation and absence of easily weathered primary minerals. Profiles P4 and P5, al so formed from colluvial materials, had a sandier surface texture than P3, and showed an E horizon overlying a fragipan. Profile P6, formed from mixed colluvium and alluvium sediments, had gray colors, massive structure, clayey texture, and low base saturation. The soil profiles were classified as Argissol (P1, P2 and P3), Planossol (P4 and P5), and Gleissol (P6).

Index terms: "Argissols", "Planossols", soil drainage.
\end{abstract}

\section{NTRODUÇÃO}

O estudo de seqüências de solos (topo, lito ou climo) tem-se mostrado eficiente para a avaliação dos efeitos dos fatores de formação (J enny, 1941) no desenvolvimento dos sol os em ecossistemas tropicais, ainda que dificilmente ocorra na paisagem uma situação onde um único fator varie, enquanto os demais permanecem constantes (Scatolini \& M oniz, 1992; Silva, 1993).

O relevo é considerado um fator que modifica o efeito dos demais fatores de formação dos solos. Fanning \& Fanning (1989) destacam a distribuição da umidade na paisagem, as diferenças na temperatura dos solos causadas pela altitude e exposição ao sol, a intensidade dos processos de remoção de sólidos e solutos (erosão e lixiviação), a remoção e deposição de sedimentos e as variações no nível do lençol freático como aspectos influenciados pel orelevo ou pela posição topográfica.

O material de origem e as suas diversas alterações nos processos de denudação, erosão e agradação das superficies, durante cicl os geológicos e climáticos, também contribuem para a pedogênese (Bigarella et al., 1965). Pesquisas real izadas em sol os desenvolvidos a partir de sedimentos inconsolidados ou que receberam contribuição de sedimentos préintemperizados (Silva, 1993; Duarte et al., 1996; Anjos, 1998) demonstraram que, em alguns solos, algumas de suas características foram herdadas diretamente do próprio material de origem.

A área do presente estudo, local izada no campus da Universidade Federal Rural do Rio de J aneiro
(UFRRJ ), apresenta al gumas feições geomorfológicas e litoestratigráficas típicas da Baixada Litorânea Fluminense, representadas pelas colinas e depressões assoreadas e pelas planícies colúvioaluvionares e aluvionares (Goes, 1994). Com o objetivo de avaliar a influência dos materiais de origem, rochas do Pré-Cambriano e sedimentos coluviais e aluvionais delas derivados, e da posição topográfica na gênese de solos, foi escolhida uma toposseqüência típica, onde os perfis de solos representam a variação destes fatores de formação.

\section{MATERIAL E MÉTODOS}

\section{Meio físico}

Segundo Goes (1994), a Baixada Litorânea Fluminense apresenta como traços estruturais um sistema de encostas, representado pelos terrenos altos de serras com material de origem do cristalino; um conjunto de colinas de topografia convexacôncava, com formações superficiais e associações litoestratigráficas, por vezes indicadas por linhas de seixos angulosos e, ou, subarredondados (Duarte et al., 1996), e as planícies colúvio-aluvionares e aluvionares, que compõem a Baixada de Sepetiba.

As feições de topos arredondados e vertentes côncavo-convexas representam remanescentes do embasamento cristalino, rochas do Pré-Cambriano, queforam retrabal hadas e originaram os sedimentos coluviais e aluviais, aos quais as colinas estão associadas na paisagem (Leonardos \& Fyfe, 1974; 
Amador, 1980; Goes, 1994; Rio de J aneiro, 1995). Segundo Goes (1994), no Hol oceno Subatual (6-5 mil anos antes do presente), formaram-se rampas de colúvio dissecadas e ombreiras associadas às col inas estruturais, além de terraceamento e depressões alveolares colúvio-aluvionares, definindo as feições geomorfológicas atuais.

O clima atual da região, segundo Köppen, é do tipo Aw, quente e úmido sem inverno pronunciado, com período chuvoso no verão e uma estiagem não muito rigorosa no inverno. A Baixada Litorânea Fluminense apresentava-se originalmente coberta pelas florestas (subperenifólia e subcaducifólia) da Mata Atlântica (EMBRAPA, 1980).

\section{Caracterização dos solos}

A toposseqüência estudada localiza-seno Campus da UFRRJ , Seropédica (RJ ). Os seis perfis de solo utilizados na pesquisa foram selecionados em uma vertente com $5 \%$ de declive e cerca de $500 \mathrm{~m}$ de comprimento, após tradagens ao longo da pendente em intervalos de, no máximo, $50 \mathrm{~m}$. Os perfis $\mathrm{P} 1 \mathrm{e}$ P2, localizados no terço superior da encosta (Figura 1), apresentaram como material de origem gnaisses leuco e mesocromáticos (Leonardos \& Fyfe, 1974; Goes, 1994). O perfil P3, localizado no terço médio da vertente, em uma seção aplainada, originou-se de sedimentos coluviais de natureza argilo-arenosa, resultantes do intemperismo das rochas citadas. J á os perfis $\mathrm{P} 4$ eP5, situados no terço inferior de encosta, tiveram como material parental os sedimentos colúvio-al uvionais (Silva, 1993; Goes, 1994). O perfil P6, na parte mais baixa da paisagem, originou-se da mistura de sedimentos fluviais, pelo transbordamento de rios em seus primitivos leitos e materiais carreados pelas águas pluviais e depositados nas cotas mais baixas (Goes, 1994).

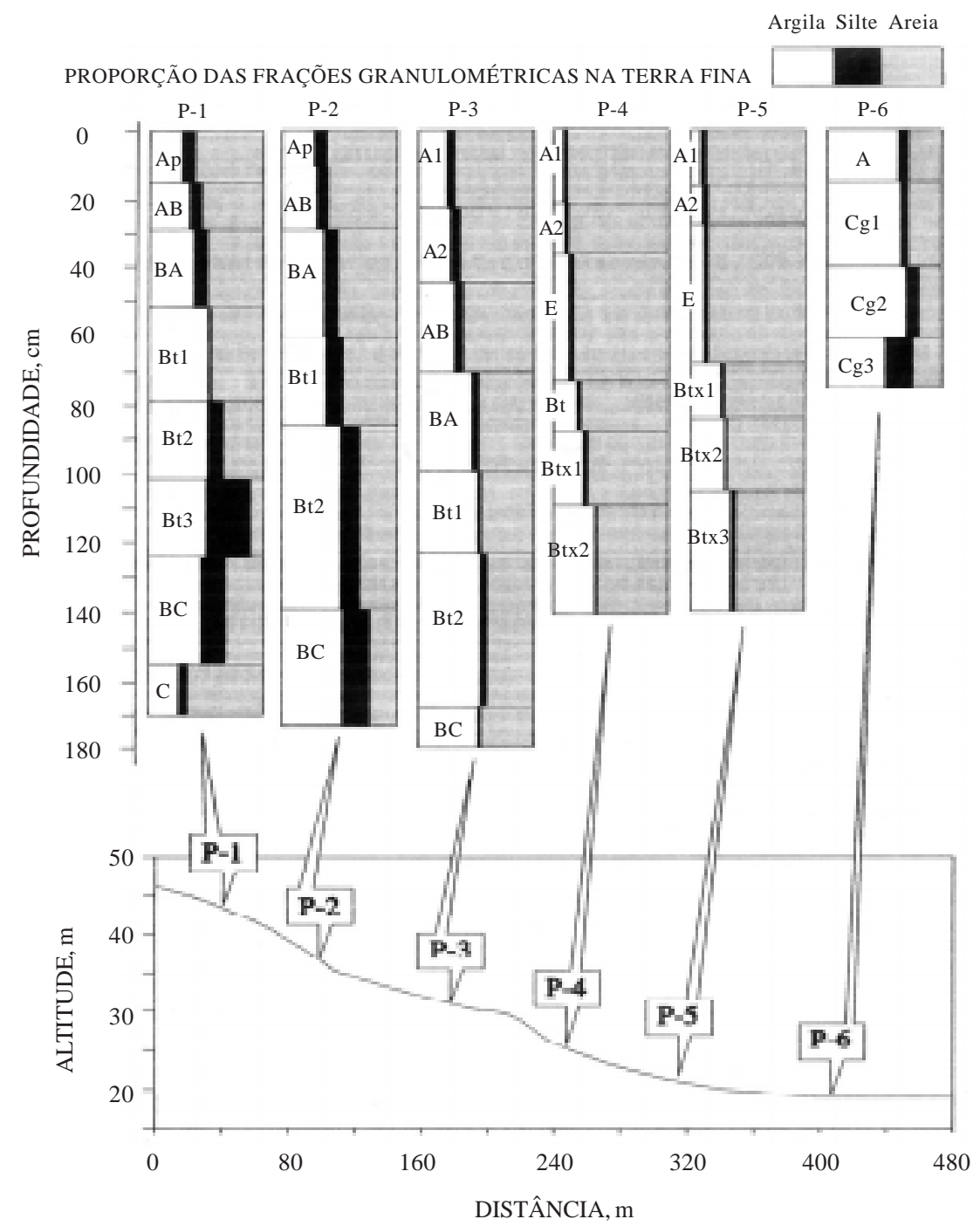

Figura 1. Localização dos perfis na toposseqüência e distribuição das frações granulométricas em profundidade. A escala no canto superior direito indica o padrão usado para representar a proporção dos componentes areia, silte e argila, em cada horizonte e perfil de solo. 
A amostragem dos sol os ea descrição morfol ógica foram realizadas segundo Lemos \& Santos (1984). As anál ises físicas equímicas seguiram recomendações da EMBRAPA (1979). Foram determinados a granulometria (método da pipeta), o teor de argila dispersa em água e a densidade do solo (método do anel volumétrico), bem como cal culados o grau defloculação e a relação silte/argila. As determinações químicas incluíram o carbono orgânico, obtido pelo método volumétrico após oxi dação pelo bicromato de potássio 0,2 mol L-1. O cálcio, magnésio e alumínio trocáveis foram extraídos com solução de $\mathrm{KCl}^{\mathrm{mol} \mathrm{L}^{-1} \mathrm{e}}$ determinados por titulação com solução de EDTA $0,0125 \mathrm{~mol} \mathrm{~L}^{-1}$, sendo o Al titulado com $\mathrm{NaOH}$ $0,025 \mathrm{~mol} \mathrm{~L}^{-1}$. O sódio e o potássio trocáveis foram extraídos com solução Mehlich-1 e quantificados por espectrofotometria de chama. Para determinar a acidez trocável $(\mathrm{H}+\mathrm{Al})$, foi feita a extração com solução de acetato de cálcio 0,5 $\mathrm{mol} \mathrm{L}^{-1}$ a pH 7,0. Além destas análises, foi determinado o pH em água ecalculadas a soma de bases (S), capacidade detroca de cátions $(T)$, saturação por bases $(\mathrm{V} \%)$ e atividade da fração argila (CTC da argila).

As formas de ferro de baixa cristalinidade (Feo) foram extraídas com oxalato ácido de amônio $0,2 \mathrm{~mol} \mathrm{~L}^{-1}$ (Schwertmann, 1964). Os óxidos de ferro pedogênicos, representados como Fed, compreendendo as formas de baixa cristalinidade (Feo) e as formas mais cristalinas, foram extraídos com solução de ditionito-citrato-bicarbonato de sódio (Mehra \& J ackson, 1960; Schulze, 1984). Os teores de Fe (Fes), $\mathrm{Al}$, Si e Ti extraíveis pelo ataque ácido $\left(\mathrm{H}_{2} \mathrm{SO}_{4} 1: 1\right)$ foram determinados por colorimetria e absorção atômica (EMBRAPA, 1979). SegundoVettori (1976), a determinação do Feextraído pel oataqueácido (Fes) parece quantificar todos os óxidos de ferro pedogênicos, mais o ferro ligado ao titânio para formar a ilmenita e o ferro que esteja presente na estrutura dos minerais silicatados, sendo assim o valor obtido de Fes é uma estimativa do teor total deste el emento no sol o. O ponto de carga zero (PCZ) foi obtido segundo o método proposto por U ehara \& Gillman (1981).

Os minerais da fração areia foram identificados semiquantitativamente por métodos óticos. Os minerais na fração argila foram identificados em difratogramas de raios- $X$, obtidos em lâminas orientadas, em aparelho do tipo Rigaku, com radiação de Cu Ka $(\lambda 0,154050 \mathrm{~nm})$, operando a uma tensão de $20 \mathrm{Kv}$ e corrente de $30 \mathrm{~mA}$ (EMBRAPA, 1979).

\section{RESULTADOS E DISCUSSÃO}

\section{Propriedades dos solos}

A cor e o grau de agregação dos horizontes subsuperficiais apresentaram forte relação com a drenagem, condicionada pela posição topográfica (Quadro 1). Os perfis bem a moderadamente drenados (P1, P2 e P3) tiveram melhor agregação, com estrutura moderada em blocos angulares e subangulares no horizonte $\mathrm{B}$. Nos perfis $\mathrm{P} 4$ e P5, ambos com drenagem imperfeita, observou-se, nos horizontes Btx, um padrão de prismas poligonais, de grau de desenvolvimento fraco, delimitado pela existência decores vermel ho-amarel adas al ternadas com uma matriz de solo cinzenta. Nesses perfis, a formação de estruturas poligonais estava condicionada à drenagem imperfeita dos solos.

Segundo Moniz (1980), por permanecerem úmidos e expandidos durante longo período de tempo, os sol os desenvolvem grandes agregados, comumente na forma prismática. O aumento na densidade do sol o nos horizontes Btx, perfis P4 eP5, está relacionado com a formação do fragipã. Segundo o model o de gênese de fragi pã apresentado no Soil Taxonomy (Estados Unidos, 1999, p.40-41), a maior densidade do sol o no fragi pã está relacionada com o pequeno grau de expansão e contração que ocorre nestes horizontes. Além destefator, o desenvol vimento do sistema radicular geral mente se dá apenas entre os prismas e é predominantemente vertical, da mesma forma que o fluxo de água. O perfil P6, mal drenado, não apresentou agregação nos horizontes Cg2 e Cg3, de estrutura maciça.

Também ocorreram variações nas cores dos sol os, dependendo da drenagem interna (Quadro 1), predominando cores vermel has (2,5YR 4/8 e 5/8) a vermel ho-amarelas (5YR 5/6 e 5/8) e amarelo brunadas (10YR 6/8) nos solos bem drenados a moderadamente drenados, P1, P2 e P3, respectivamente, e cores cinzentas (10YR 5/1, 5/2 e 6/1) nos perfis imperfeitamente e mal drenados (perfis P4, $\mathrm{P} 5$ e P6). Os mosqueados observados nos perfis $\mathrm{P} 4$, P5 e P6, nas zonas sujeitas à saturação com água, resultaram da presença de condições desuniformes de oxidação; nos perfis P4 e P5, estes mosqueados, dominantemente bruno-amarelados (10YR 5/8), concentraram-se nas faces dos polígonos. Esta local ização deveu-se, provavel mente, à mi gração do ferro $\left(\mathrm{Fe}^{2+}\right)$ para as zonas com maior aeração formadas durante o período de secamento do solo, onde o ferro é oxidado a $\mathrm{Fe}^{3+}$, assemel hando ao model o de mosqueado I deFanning \& Fanning (1989, págs.115-116), em que o $\mathrm{Fe}^{2+}$ é solubilizado no interior dos prismas e se difunde para a superfície. $\mathrm{O}$ padrão de mosqueado observado nos perfis $\mathrm{P} 4 \mathrm{e}$ P5, notadamente no fragipã, apresentou cores semelhantes as verificadas por Smith \& Callahan (1987); entretanto, a distribuição foi distinta, já que as cores cinzentas não foram obser vadas no contato entre os prismas, como citado no Soil Taxonomy (Estados Unidos, 1999, pág.40) na descrição do fragipã.

Tal comportamento pode ser devido aos períodos em que dominam as condições de redução no solo, ao longo do ano, resultantes da lenta permeabilidade 
do perfil, notopo do horizonte B (lençol suspenso), eà própria condição dedrenagem imperfeita dosolo, sem, contudo, caracterizar a presença de um horizonteglei.

A granulometria dos solos mostrou grande variação aol ongo da encosta (Figura 1). Os perfis P1, P2 e P3 apresentaram textura média/argilosa, P4 e
P5 textura arenosa/média e o perfil P6 textura argilosa. Verificou-se, na seqüência dos perfis, uma distribuição irregular na granulometria dos horizontes superficiais dos perfis P3, P4 e P5, em relação à sua posição na vertente. O material mais argil oso foi observado no terço médio da encosta (P3)

Quadro 1. Atributos morfológicos e físicos dos perfis estudados

\begin{tabular}{|c|c|c|c|c|c|c|c|}
\hline \multirow{2}{*}{ Horizonte } & \multirow{2}{*}{ Profundidade } & \multicolumn{2}{|c|}{ Cor úmida } & \multirow{2}{*}{ Estrutura(1) } & \multirow{2}{*}{ Argila total } & \multirow{2}{*}{ Silte/argila } & \multirow{2}{*}{ Ds(3) } \\
\hline & & Matriz & Mosqueado & & & & \\
\hline \multicolumn{3}{|c|}{$\mathrm{cm}$} & & & $\mathrm{g} \mathrm{kg}^{-1}$ & & $\mathrm{~kg} \mathrm{dm}^{-3}$ \\
\hline \multicolumn{8}{|c|}{ P1 - Argissolo Vermel ho-Amarelo } \\
\hline $\begin{array}{l}\text { Ap } \\
\text { AB } \\
\text { BA } \\
\text { Bt1 } \\
\text { Bt2 } \\
\text { Bt3 } \\
\text { BC } \\
\text { C }\end{array}$ & $\begin{array}{r}0-15 \\
-29 \\
-52 \\
-79 \\
-102 \\
-124 \\
-155 \\
-170^{+}\end{array}$ & $\begin{array}{l}10 Y R 3 / 3 \\
10 Y R 4 / 4 \\
7,5 Y R 5 / 8 \\
7,5 Y R 5 / 8 \\
5 Y R 5 / 6 \\
2,5 Y R 4 / 8 \\
2,5 Y R 5 / 8 \\
2,5 Y R 4 / 8\end{array}$ & variegado & $\begin{array}{l}\text { fr. pq. gr. } \\
\text { fr. pq. gr. } \\
\text { mo. pq. e mé. ba. } \\
\text { mo. pq. e mé. ba. } \\
\text { mo. pq. e mé. ba. } \\
\text { mo. pq. e mé. ba. e bsa. } \\
\text { fr. pq. mé. ba. } \\
\text { fr. pq. ba. }\end{array}$ & $\begin{array}{l}300 \\
360 \\
390 \\
540 \\
530 \\
520 \\
460 \\
260\end{array}$ & $\begin{array}{l}0,40 \\
0,31 \\
0,31 \\
0,22 \\
0,26 \\
0,73 \\
0,75 \\
0,69\end{array}$ & $\begin{array}{l}1,41 \\
1,52 \\
1,50 \\
1,51 \\
1,40 \\
1,37 \\
1,50 \\
-\end{array}$ \\
\hline \multicolumn{8}{|c|}{ P2 - Argissolo Vermelho-Amarelo } \\
\hline $\begin{array}{l}\text { Ap } \\
\text { AB } \\
\text { BA } \\
\text { Bt1 } \\
\text { Bt2 } \\
\text { BC }\end{array}$ & $\begin{array}{r}0-10 \\
-29 \\
-60 \\
-86 \\
-140 \\
-174^{+}\end{array}$ & $\begin{array}{l}\text { 10YR } 3 / 3 \\
10 Y R 4 / 4 \\
7,5 Y R 5 / 6 \\
5 Y R 5 / 6 \\
5 Y R 5 / 8 \\
5 Y R 5 / 8\end{array}$ & $\begin{array}{l}- \\
-\end{array}$ & $\begin{array}{l}\text { fr. pq. gr. } \\
\text { fr. pq. gr. } \\
\text { fr. pq. bsa. } \\
\text { mo. pq. ba. } \\
\text { mo. pq. e mé. ba. } \\
\text { mo. pq. e mé. ba. }\end{array}$ & $\begin{array}{l}290 \\
310 \\
370 \\
410 \\
510 \\
510\end{array}$ & $\begin{array}{l}0,45 \\
0,35 \\
0,30 \\
0,29 \\
0,33 \\
0,33\end{array}$ & $\begin{array}{l}1,51 \\
1,52 \\
1,56 \\
1,45 \\
1,43 \\
1,43\end{array}$ \\
\hline \multicolumn{8}{|c|}{ P3 - Argissolo Amarelo } \\
\hline $\begin{array}{l}\text { A1 } \\
\text { A2 } \\
\text { AB } \\
\text { BA } \\
\text { Bt1 } \\
\text { Bt2 } \\
\text { BC }\end{array}$ & $\begin{array}{r}0-22 \\
-44 \\
-70 \\
-99 \\
-123 \\
-168 \\
-187^{+}\end{array}$ & $\begin{array}{l}\text { 1OYR } 3 / 3 \\
10 Y R 4 / 3 \\
10 Y R 5 / 6 \\
10 Y R 5 / 6 \\
10 Y R 6 / 8 \\
10 Y R 6 / 8 \\
10 Y R 6 / 8\end{array}$ & $\begin{array}{l}- \\
- \\
-\end{array}$ & $\begin{array}{l}\text { fr. pq. gr. } \\
\text { fr. pq. gr. } \\
\text { fr. pq. gr. } \\
\text { mo. pq. e mé. ba. e bsa. } \\
\text { mo. pq. e mé. ba. e bsa. } \\
\text { mo. pq. e mé.ba. } \\
\text { fr. pq. ba. }\end{array}$ & $\begin{array}{l}250 \\
270 \\
320 \\
470 \\
510 \\
540 \\
510\end{array}$ & $\begin{array}{l}0,28 \\
0,33 \\
0,19 \\
0,11 \\
0,10 \\
0,11 \\
0,10\end{array}$ & $\begin{array}{l}1,54 \\
1,59 \\
1,45 \\
1,54 \\
1,41 \\
1,42 \\
1,31\end{array}$ \\
\hline \multicolumn{8}{|c|}{ P4 - Planossolo Háplico } \\
\hline $\begin{array}{l}\text { A1 } \\
\text { A2 } \\
\text { E } \\
\text { Bt } \\
\text { Btx1 }\end{array}$ & $\begin{array}{r}0-21 \\
-37 \\
-73 \\
-88 \\
-110\end{array}$ & $\begin{array}{l}\text { 10YR } 3 / 2 \\
\text { 10YR } 4 / 1 \\
\text { 10YR } 5 / 2 \\
\text { 10YR 5/1 } \\
\text { 10YR 5/2 }\end{array}$ & $\begin{array}{c}- \\
- \\
- \\
\text { 1OYR } 5 / 8 \\
\text { 1OYR } 5 / 8\end{array}$ & $\begin{array}{l}\text { fr. pq. e mé. gr. } \\
\text { fr. pq. gr. } \\
\text { fr. pq. e mé. bsa. } \\
\text { fr. pq. e mé. bsa. e ba. } \\
\text { fr. desenv. pad. polig }{ }^{(2)}\end{array}$ & $\begin{array}{r}80 \\
100 \\
110 \\
220 \\
280\end{array}$ & $\begin{array}{l}0,50 \\
0,60 \\
0,36 \\
0,14 \\
0,07\end{array}$ & $\begin{array}{l}1,52 \\
1,68 \\
1,67 \\
1,74 \\
1,78\end{array}$ \\
\hline Btx2 & $-142^{+}$ & 10YR 5/2 & $\begin{array}{l}2,5 Y R 4 / 8 \text { e } \\
10 Y R 5 / 8\end{array}$ & fr. desenv. pad. polig(2) & 370 & 0,03 & 1,72 \\
\hline \multicolumn{8}{|c|}{ P5 - Planossolo Háplico } \\
\hline $\begin{array}{l}\text { A1 } \\
\text { A2 } \\
\text { E } \\
\text { Btx1 } \\
\text { Btx2 }\end{array}$ & $\begin{array}{r}0-16 \\
-28 \\
-68 \\
-84 \\
-106\end{array}$ & $\begin{array}{l}10 Y R 3 / 2 \\
10 Y R 4 / 1 \\
10 Y R 6 / 2 \\
10 Y R 6 / 1 \\
10 Y R 5 / 1\end{array}$ & $\begin{array}{c}- \\
- \\
- \\
\text { 10YR } 5 / 8 \\
\text { 10YR } 5 / 8\end{array}$ & $\begin{array}{l}\text { fr. pq. gr. } \\
\text { fr. pq. gr. } \\
\text { fr. pq. gr. } \\
\text { fr. desenv. pad. polig(2) } \\
\text { fr. desenv. pad. polig } g^{(2)}\end{array}$ & $\begin{array}{r}90 \\
100 \\
120 \\
380 \\
420\end{array}$ & $\begin{array}{l}0,44 \\
0,70 \\
0,42 \\
0,03 \\
0,01\end{array}$ & $\begin{array}{l}1,44 \\
1,57 \\
1,60 \\
1,71 \\
1,60\end{array}$ \\
\hline Btx3 & $-141^{+}$ & 10YR 6,5/1 & $\begin{array}{l}2,5 Y R \quad 4 / 6 \text { e } \\
10 Y R 6 / 8\end{array}$ & fr. desenv. pad. polig $g^{(2)}$ & 480 & 0,06 & 1,55 \\
\hline \multicolumn{8}{|c|}{ P6 - Gleissolo Háplico } \\
\hline A & $0-15$ & 10YR 3/1 & - & fr. pq. gr. & 630 & 0,14 & 0,64 \\
\hline $\mathrm{Cg} 1$ & -40 & $10 Y R 5 / 1$ & $5 Y R$ 4/4 & fr. pq. e mé. gr. e ba. & 670 & 0,06 & 1,16 \\
\hline $\mathrm{Cg} 2$ & -61 & $\mathrm{~N} 3,5 / 0$ & $5 Y R \quad 4 / 6$ & maciça & 690 & 0,16 & 1,07 \\
\hline Cg3 & $-75^{+}$ & $10 Y R 6 / 1$ & 7,5YR 5/6 & maciça & 500 & 0,48 & 1,42 \\
\hline
\end{tabular}

(1) fr. = fraca; mo.= moderada; pq.= pequena; mé.= média; gr.= granular; ba.= blocos angulares; bsa.= blocos subangulares. ${ }^{(2)}$ pad. polig = padrão poligonal associado ao fragi pã, com arranjamento estrutural em prismas, definidos por mosqueados de cores distintas da matriz (Estados Unidos, 1993). ${ }^{(3)} \mathrm{Ds}=$ densidade do solo. 
e o mais arenoso nas posições inferiores (P 4 e P5), contrariando a tendência natural das partículas mais finas de serem arrastadas para as partes mais baixas.

Essa aparente inversão na granulometria deveuse a uma quebra de gradiente no terço médio da encosta, provocando uma redução na vel ocidade de arraste das partículas e conseqüente deposição do material mais fino, bem como variações de granulometria nos sedimentos coluvionais, relacionadas com os distintos períodos de sedimentação. A relação silte/ argila nos perfis P4 e P5 (Quadro 1) diminuiu gradualmente entre os horizontes $\mathrm{A}$ e $\mathrm{E}$ e então reduziu, de forma brusca, para os horizontes com fragipã.

O complexo sortivo (Quadro 2) dos solos foi influenciado simultaneamente pela posição topográfica e pelo material originário. Os perfis $\mathrm{P} 1$ e P2 apresentaram valor S variando de 24,3 a $41,2 \mathrm{mmol}_{\mathrm{C}} \mathrm{kg}^{-1}$ e saturação por bases ligeiramente acima de $50 \%$. Os perfis P3, P4 e P5, formados a partir da cobertura sedimentar pré-edafizada, mostraram complexo sortivo dessaturado, o maior val or $\mathrm{S}$ foi de $14,1 \mathrm{mmol}_{\mathrm{c}} \mathrm{kg}^{-1}(\mathrm{P3}, \mathrm{A} 1)$. No perfil $\mathrm{P} 6$, o valor S variou de 38,4 a $47,4 \mathrm{mmol}_{\mathrm{C}} \mathrm{kg}^{-1}$. Na planície aluvionar, além da própria natureza dos sedimentos, percebeu-se uma contribuição de bases lixiviadas dos terrenos mais altos via fluxo lateral subsuperficial (Moniz, 1980). Demodogeral, oH +Al dominaram o complexo sortivo dos perfis originados de sedimentos (P3, P4, P5 e P6), ea saturação por Al (m) foi superior a $50 \%$, na maioria dos horizontes. J á para os perfis desenvolvidos do gnaisse (P1 e P2) predomi naram os íons $\mathrm{Ca}^{2+}$ e $\mathrm{M} \mathrm{g}^{2+}$, o que se refletiu em $\mathrm{pH}$ mais elevado. Todos os perfis apresentaram argila de baixa atividade (CTC inferior a $27 \mathrm{cmol}_{\mathrm{C}} \mathrm{kg}^{-1}$ de argila), com valor $\mathrm{T}$ ligeiramente superior no P6 e nos horizontes superficiais, este último ligado à distribuição de carbono orgânico.

A relação ki (Quadro 3) nos horizontes diagnósticos subsuperficiais variou de 1,56 a 2,0, indicando o predomínio na fração argila de minerais do grupo da caulinita e óxidos de alumínio (Nascimento, 1989). Entre os perfis, os maiores valores de ki foram observados em horizontes dos perfis $\mathrm{P} 4$ e $\mathrm{P} 5$, indicando que a textura arenosa estaria influenciando a relação ki, pel o aumento dos teores de Si. Ainda que a posição topográfica do perfil P6 na vertente favoreça a ressilicificação da argila pelo enriquecimento da solução em sílica e bases (Moniz, 1980; Demattê et al., 1992), esta transformação não ocorreu, como envidenciada pela mineralogia da argila no horizonte Cg2, que indica o domínio de caulinita e a presença de gibbsita (Figura 2). Apesar do menor PCZ $(2,5)$ no horizonte Cg2 do perfil P6, os valores de PCZ em geral foram baixos.

Quanto às formas de ferro (Quadro 3), os teores deFes variaram de 3 a $90 \mathrm{~g} \mathrm{~kg}^{-1}$ TFSA, e, com exceção do perfil P6, Fes aumentou nos horizontes subsuperficiais. O teor deFes decresceu da partealta da encosta até à planície (do perfil P1 ao P6), acompanhando a variação na drenagem dos solos. Anal isando a relaçãoFeo/Fed, verificou-se queo mais alto val or $(0,14)$ correspondeu ao perfil P6 (Cg2), com mais sérias restrições à drenagem. Nos perfis $\mathrm{P} 1$, P2 e P3, a relação Feo/Fed indicou um aumento das formas de Fe de baixa cristalinidade nos horizontes superficiais, provavel mente pelo maior teor da fração orgânica desses horizontes, inibindo a cristalização (Schwertmann \& Kämpf, 1983; Schwertmann \& Taylor, 1989). Quantoà relação Fed/Fes, houve pouca variação entre os horizontes superficiais e subsuperficiais nos perfis P1, P2 eP3, querevelaram drenagem boa a moderada. Nos perfis P4 e P5, percebeu-se um aumento de Fed/Fes em mais de cinco vezes no horizonte Btx2 (0,76 e 0,89, respectivamente), indicando maior proporção do $\mathrm{Fe}$ na forma de óxidos, evidenciados nas zonas de oxidação entre os prismas pelos mosqueados de cor avermelhada (matiz 2,5YR) e amarelada (matiz 10YR). As relações Fed/Fes e Feo/Fed estão relacionadas com a classe de drenagem dos solos.

A mineral ogia da fração areia (Quadro 4) refletiu a influência do material originário dos solos. Nos perfis originados da rocha gnáissica ( $\mathrm{P} 1$ e P2), foram observados maiores teores de minerais primários facilmente intemperizáveis (mica e feldspatos), ao contrário do que ocorreu nos demais sol os originados de sedimentos pré-edafizados, onde a fração areia é dominada pelo quartzo. A análise mineralógica da fração argila, por difração de raios-X (Figura 2), revelou o predomínio de caulinita, acompanhada de vermiculita hidróxi-interestratificada (VHE) e goethita em todos os perfis. No perfil P6, foi também identificada a gibbsita e observou-se melhor expressão do mi neral ilita (mica). Duarteet al. (1996) verificaram comportamento similar em solos desenvolvidos de cobertura quaternária sobre embasamento cristalino, localizados na baixada litorânea do estado do Rio de J aneiro.

\section{Pedogênese e classificação}

O sentido e a intensidade do fluxo de água em uma encosta, que variam de acordo com a topografia e forma da superfície, são as principais causas da diferenciação dos solos ao longo detoposseqüências. A natureza e a intensidade dos processos pedogenéticos, que resultaram na variação dos sol os observada na toposseqüência, foram fortemente influenciadas pela posi ção topográfica e pela própria disposição do material parental dos solos.

Os perfis $\mathrm{P} 1$ e P2, com seqüência de horizontes ABtC, apresentaram grau de diferenciação de horizontes comparável à dos perfis P4 e P5, apesar do maior teor de minerais primários menos resistentes ao intemperismo (micas e fel dspatos). A convexidade da superfície onde estãolocal izados P1 
Quadro 2. Complexo de troca dos perfis estudados

\begin{tabular}{|c|c|c|c|c|c|c|c|c|c|c|c|}
\hline \multirow{2}{*}{ Horizonte } & \multirow{2}{*}{$\mathrm{pH} \mathrm{H}_{2} \mathrm{O}$} & \multicolumn{5}{|c|}{ Complexo de troca } & \multirow{2}{*}{$\mathbf{s}$} & \multirow{2}{*}{$\mathbf{T}$} & \multirow{2}{*}{$\mathbf{v}$} & \multirow{2}{*}{$\mathbf{m}$} & \multirow{2}{*}{ C } \\
\hline & & $\mathrm{Ca}^{2+}$ & $\mathbf{M g}^{2+}$ & $\mathbf{K}^{+}$ & $\mathbf{H}^{+}$ & $\mathbf{A l}^{3+}$ & & & & & \\
\hline & & \multicolumn{7}{|c|}{$\mathrm{mmol}_{\mathrm{c}} \mathrm{kg}^{-1} \mathrm{TFSA}$} & \multicolumn{2}{|c|}{ — $\%$} & $\mathrm{~g} \mathrm{~kg}^{-1}$ \\
\hline \multicolumn{12}{|c|}{ P1 - Argissolo Vermel ho-Amarelo } \\
\hline Ap & 5,8 & 19 & 18 & 3,2 & 37 & 3 & 41,2 & 81,2 & 51 & 7 & 19,0 \\
\hline$A B$ & 5,5 & 13 & 10 & 1,1 & 29 & 4 & 24,6 & 57,6 & 43 & 14 & 9,6 \\
\hline $\mathrm{BA}$ & 6,1 & 15 & 10 & 0,4 & 20 & 0 & 25,8 & 45,8 & 56 & 0 & 7,6 \\
\hline Bt1 & 6,3 & 13 & 14 & 0,5 & 18 & 0 & 28,1 & 46,1 & 61 & 0 & 5,5 \\
\hline $\mathrm{Bt} 2$ & 6,3 & 11 & 19 & 0,7 & 19 & 0 & 32,1 & 51,1 & 63 & 0 & 4,8 \\
\hline $\mathrm{Bt} 3$ & 6,2 & 11 & 21 & 0,4 & 20 & 0 & 34,8 & 54,8 & 64 & 0 & 4,5 \\
\hline $\mathrm{BC}$ & 6,0 & 5 & 24 & 0,4 & 20 & 0 & 31,9 & 51,9 & 62 & 0 & 3,8 \\
\hline $\mathrm{C}$ & 5,6 & 1 & 22 & 0,5 & 14 & 14 & 25,1 & 53,1 & 47 & 0 & 2,6 \\
\hline \multicolumn{12}{|c|}{ P2 - Argissolo Vermel ho-Amarelo } \\
\hline Ap & 5,6 & 14 & 17 & 2,0 & 31 & 4 & 33,8 & 68,8 & 49 & 11 & 15,0 \\
\hline$A B$ & 5,4 & 10 & 13 & 0,8 & 30 & 7 & 24,3 & 61,3 & 40 & 22 & 10,1 \\
\hline $\mathrm{BA}$ & 5,6 & 9 & 15 & 0,5 & 23 & 3 & 25,0 & 51,0 & 49 & 11 & 5,1 \\
\hline Bt1 & 5,8 & 7 & 16 & 0,5 & 21 & 2 & 24,4 & 47,4 & 52 & 8 & 4,8 \\
\hline Bt2 & 5,8 & 5 & 26 & 0,5 & 23 & 7 & 33,1 & 63,1 & 52 & 17 & 3,5 \\
\hline $\mathrm{BC}$ & 5,6 & 2 & 28 & 0,8 & 19 & 11 & 32,5 & 62,5 & 52 & 25 & 2,3 \\
\hline \multicolumn{12}{|c|}{ P3 - Argissolo Amarelo } \\
\hline Al & 5,2 & 5 & 8 & 0,7 & 37 & 9 & 14,1 & 60,1 & 23 & 39 & 10,9 \\
\hline $\mathrm{A} 2$ & 5,0 & 4 & 4 & 0,4 & 28 & 11 & 8,7 & 47,7 & 18 & 56 & 8,4 \\
\hline$A B$ & 5,1 & 3 & 5 & 0,2 & 18 & 11 & 8,4 & 37,4 & 22 & 57 & 4,6 \\
\hline $\mathrm{BA}$ & 4,9 & 4 & 3 & 0,1 & 25 & 20 & 7,4 & 52,4 & 14 & 73 & 4,1 \\
\hline Bt1 & 4,8 & 1 & 2 & 0,1 & 22 & 24 & 3,4 & 49,4 & 7 & 88 & 4,0 \\
\hline $\mathrm{Bt} 2$ & 4,9 & 2 & 2 & 0,1 & 19 & 20 & 4,6 & 43,6 & 11 & 81 & 3,8 \\
\hline $\mathrm{BC}$ & 5,0 & 3 & 4 & 0,1 & 17 & 15 & 7,5 & 39,5 & 19 & 67 & 3,3 \\
\hline \multicolumn{12}{|c|}{ P4 - Planossolo Háplico } \\
\hline A1 & 5,4 & 3 & 2 & 0,9 & 24 & 5 & 6,5 & 35,5 & 18 & 43 & 7,3 \\
\hline A2 & 5,3 & 1 & 1 & 0,3 & 16 & 6 & 2,8 & 24,8 & 11 & 68 & 4,5 \\
\hline $\mathrm{E}$ & 5,2 & 1 & 1 & 0,4 & 12 & 8 & 2,8 & 22,8 & 12 & 74 & 2,3 \\
\hline $\mathrm{Bt}$ & 5,4 & 2 & 3 & 0,4 & 13 & 11 & 5,8 & 29,8 & 20 & 65 & 2,2 \\
\hline Btx1 & 5,4 & 3 & 3 & 0,6 & 16 & 14 & 7,2 & 37,2 & 19 & 66 & 2,3 \\
\hline Btx2 & 5,4 & 3 & 7 & 0,7 & 14 & 13 & 11,4 & 38,4 & 30 & 53 & 2,5 \\
\hline \multicolumn{12}{|c|}{ P5 - Planossolo Háplico } \\
\hline A1 & 5,4 & 4 & 4 & 0,8 & 27 & 5 & 9,2 & 4,1 & 22 & 35 & 9,7 \\
\hline$A 2$ & 5,1 & 1 & 2 & 0,3 & 16 & 8 & 3,6 & 2,8 & 13 & 69 & 4,7 \\
\hline & 5,2 & 2 & 0 & 0,3 & 09 & 7 & 2,5 & 1,9 & 14 & 74 & 2,6 \\
\hline Btx1 & 5,1 & 4 & 5 & 0,1 & 15 & 21 & 9,7 & 4,6 & 21 & 68 & 2,6 \\
\hline Btx2 & 5,1 & 3 & 6 & 0,1 & 15 & 24 & 9,7 & 4,9 & 20 & 71 & 2,3 \\
\hline Btx3 & 5,0 & 3 & 3 & 0,3 & 13 & 30 & 7,0 & 5,0 & 14 & 81 & 2,2 \\
\hline \multicolumn{12}{|c|}{ P6 - Gleissolo Háplico } \\
\hline A & 4,5 & 23 & 11 & 1,8 & & & 41,6 & & 19 & 47 & 45,7 \\
\hline $\mathrm{Cgl}$ & 4,9 & 24 & 12 & 0,1 & 38 & 21 & 38,4 & 91,4 & 42 & 35 & 6,6 \\
\hline $\mathrm{Cg} 2$ & 5,0 & 28 & 17 & 0,1 & 47 & 19 & 47,4 & 97,4 & 49 & 29 & 4,9 \\
\hline Cg3 & 5,0 & 25 & 15 & 0,1 & 42 & 12 & 41,7 & 72,7 & 57 & 22 & 3,2 \\
\hline
\end{tabular}

$\mathrm{S}=\mathrm{Ca}+\mathrm{Mg}+\mathrm{K}+\mathrm{Na} ; \mathrm{T}=\mathrm{S}+(\mathrm{H}+\mathrm{Al}) ; \mathrm{V}=100 \times \mathrm{S} / \mathrm{T} ; \mathrm{m}=100 \times \mathrm{Al}^{+3} /\left(\mathrm{Al}{ }^{+3}+\mathrm{S}\right)$.

e P2, associada à sua posição topográfica, favoreceu a remoção das camadas superficiais do solo por erosão, além de promover o aumento do escoamento superficial de água, com conseqüente menor percolação no perfil e diminuição da intensidade de intemperismo. Nos perfis P1 e P2, a estrutura em blocos moderadamente desenvolvida do horizonte $\mathrm{B}$ deve ter resultado da deformação plástica durante os cicl os de umedecimento e secagem, o que, segundo Moniz (1980), é favorecido pelo fluxo lateral subsuperficial de água no solo. A presença de cerosidade no horizonte Bt dos perfis $\mathrm{P} 1$ eP 2 indicou a atuação do mecanismo de translocação de argila nestes solos; entretanto, a intensidade do processo de eluviação de argila não foi suficiente para a formação do horizonte $\mathrm{E}$. 
Quadro 3. Formas extraíveis de $\mathrm{Si}$, Al, Fe e Ti, PCZ e relações Feo/Fed e Fed/Fes dos perfis estudados ${ }^{(1)}$

\begin{tabular}{|c|c|c|c|c|c|c|c|c|}
\hline \multirow{2}{*}{ Horizonte } & \multicolumn{4}{|c|}{ Ataque sulfúrico (1:1) } & \multirow[b]{2}{*}{$\mathbf{K i}$} & \multirow[b]{2}{*}{ PCZ } & \multirow[b]{2}{*}{ F eo/F ed } & \multirow[b]{2}{*}{ Fed/Fes } \\
\hline & $\mathrm{SiO}_{2}$ & $\mathrm{Al}_{2} \mathrm{O}_{3}$ & $\mathrm{Fe}_{2} \mathrm{O}_{3}$ & $\mathrm{TiO}_{2}$ & & & & \\
\hline \multicolumn{9}{|c|}{$-\mathrm{g} \mathrm{kg}^{-1} \mathrm{TFSA}$} \\
\hline \multicolumn{9}{|c|}{ P1 - Argissolo Vermelho-Amarelo } \\
\hline $\begin{array}{l}\text { Ap } \\
\text { AB } \\
\text { BA } \\
\text { Bt1 } \\
\text { Bt2 } \\
\text { Bt3 } \\
\text { BC } \\
\text { C }\end{array}$ & $\begin{array}{l}115,0 \\
127,6 \\
124,2 \\
160,6 \\
176,6 \\
228,0 \\
196,0 \\
224,6\end{array}$ & $\begin{array}{r}97,4 \\
107,2 \\
111,0 \\
148,2 \\
183,2 \\
203,4 \\
195,0 \\
194,2\end{array}$ & $\begin{array}{l}47,0 \\
53,0 \\
57,0 \\
67,0 \\
79,0 \\
90,0 \\
78,0 \\
83,0\end{array}$ & $\begin{array}{l}12,2 \\
11,0 \\
11,3 \\
14,2 \\
14,2 \\
13,8 \\
12,8 \\
12,6\end{array}$ & $\begin{array}{l}2,01 \\
2,03 \\
1,92 \\
1,85 \\
1,64 \\
1,91 \\
1,71 \\
1,97\end{array}$ & $\begin{array}{l}2,9 \\
- \\
- \\
3,2 \\
- \\
- \\
-\end{array}$ & $\begin{array}{l}0,06 \\
- \\
- \\
0,02 \\
- \\
- \\
-\end{array}$ & $\begin{array}{l}0,80 \\
- \\
- \\
0,74 \\
- \\
- \\
-\end{array}$ \\
\hline \multicolumn{9}{|c|}{ P2 - Argissolo Vermelho-Amarelo } \\
\hline $\begin{array}{l}\text { Ap } \\
\text { AB } \\
\text { BA } \\
\text { Bt1 } \\
\text { Bt2 } \\
\text { BC }\end{array}$ & $\begin{array}{c}99,4 \\
114, \\
126, \\
134,4 \\
173,2 \\
184,6\end{array}$ & $\begin{array}{r}86,2 \\
99,9 \\
108,5 \\
141,3 \\
190,3 \\
185,0\end{array}$ & $\begin{array}{l}43,0 \\
47,0 \\
61,0 \\
63,0 \\
84,0 \\
77,0\end{array}$ & $\begin{array}{l}11,0 \\
13,0 \\
12,0 \\
14,0 \\
12,4 \\
12,8\end{array}$ & $\begin{array}{l}1,86 \\
1,93 \\
1,98 \\
1,61 \\
1,55 \\
1,69\end{array}$ & $\begin{array}{l}2,8 \\
- \\
- \\
3,7 \\
- \\
-\end{array}$ & $\begin{array}{l}0,07 \\
- \\
- \\
0,04 \\
- \\
-\end{array}$ & $\begin{array}{l}0,64 \\
- \\
- \\
0,47 \\
- \\
-\end{array}$ \\
\hline \multicolumn{9}{|c|}{ P3 - Argissolo Amarelo } \\
\hline $\begin{array}{l}\text { A1 } \\
A 2 \\
A B \\
B A \\
\text { Bt1 } \\
\text { Bt2 } \\
\text { BC }\end{array}$ & $\begin{array}{r}67,2 \\
69,5 \\
72,9 \\
111,6 \\
123,0 \\
139,0 \\
179,0\end{array}$ & $\begin{array}{r}68,8 \\
73,3 \\
83,3 \\
149,2 \\
173,4 \\
164,7 \\
172,2\end{array}$ & $\begin{array}{l}21,0 \\
25,0 \\
25,0 \\
41,0 \\
48,0 \\
46,0 \\
48,0\end{array}$ & $\begin{array}{r}8,4 \\
9,2 \\
9,2 \\
10,9 \\
12,2 \\
11,7 \\
12,6\end{array}$ & $\begin{array}{l}1,65 \\
1,61 \\
1,49 \\
1,28 \\
1,21 \\
1,43 \\
1,77\end{array}$ & $\begin{array}{l}2,8 \\
- \\
- \\
- \\
3,5 \\
- \\
-\end{array}$ & $\begin{array}{l}0,07 \\
- \\
- \\
- \\
0,00 \\
- \\
-\end{array}$ & $\begin{array}{l}0,78 \\
- \\
- \\
- \\
0,80 \\
- \\
-\end{array}$ \\
\hline \multicolumn{9}{|c|}{ P4 - Planossolo Háplico } \\
\hline $\begin{array}{l}\text { A1 } \\
\text { A2 } \\
\text { E } \\
\text { Bt } \\
\text { Btx1 } \\
\text { Btx2 }\end{array}$ & $\begin{array}{r}28,5 \\
34,2 \\
40,4 \\
63,2 \\
88,9 \\
109,4\end{array}$ & $\begin{array}{r}10,4 \\
15,2 \\
23,1 \\
37,8 \\
69,9 \\
105,9\end{array}$ & $\begin{array}{r}5,0 \\
5,0 \\
8,0 \\
7,0 \\
14,0 \\
16,0\end{array}$ & $\begin{array}{l}4,3 \\
6,2 \\
6,3 \\
6,8 \\
8,3 \\
8,3\end{array}$ & $\begin{array}{l}4,65 \\
3,82 \\
2,97 \\
2,84 \\
2,16 \\
1,76\end{array}$ & $\begin{array}{l}3,3 \\
- \\
3,0 \\
- \\
- \\
3,0\end{array}$ & $\begin{array}{l}0,00 \\
- \\
0,00 \\
- \\
- \\
0,08\end{array}$ & $\begin{array}{l}0,20 \\
- \\
0,14 \\
- \\
- \\
0,76\end{array}$ \\
\hline \multicolumn{9}{|c|}{ P5 - Planossolo Háplico } \\
\hline $\begin{array}{l}\text { A1 } \\
\text { A2 } \\
\text { E } \\
\text { Btx1 } \\
\text { Btx2 } \\
\text { Btx3 }\end{array}$ & $\begin{array}{r}26,2 \\
37,6 \\
43,8 \\
127,6 \\
148,2 \\
125,4\end{array}$ & $\begin{array}{r}13,7 \\
21,9 \\
30,7 \\
109,6 \\
145,2 \\
144,6\end{array}$ & $\begin{array}{r}3,0 \\
4,0 \\
7,0 \\
18,0 \\
32,0 \\
38,0\end{array}$ & $\begin{array}{r}3,8 \\
6,6 \\
6,9 \\
8,7 \\
11,0 \\
10,3\end{array}$ & $\begin{array}{l}3,16 \\
2,93 \\
2,41 \\
2,00 \\
1,73 \\
1,46\end{array}$ & $\begin{array}{l}2,8 \\
- \\
2,8 \\
- \\
3,2 \\
-\end{array}$ & $\begin{array}{l}0,00 \\
- \\
0,00 \\
- \\
0,04 \\
-\end{array}$ & $\begin{array}{l}0,17 \\
- \\
0,17 \\
- \\
0,89 \\
-\end{array}$ \\
\hline \multicolumn{9}{|c|}{ P6 - Gleissolo Háplico } \\
\hline $\begin{array}{l}\text { A } \\
\text { Cg1 } \\
\text { Cg2 } \\
\text { Cg3 }\end{array}$ & $\begin{array}{l}208,6 \\
204,0 \\
192,6 \\
136,8\end{array}$ & $\begin{array}{l}174,2 \\
193,9 \\
191,0 \\
149,2\end{array}$ & $\begin{array}{l}23,0 \\
27,0 \\
24,0 \\
19,0\end{array}$ & $\begin{array}{l}12,6 \\
14,6 \\
14,4 \\
12,6\end{array}$ & $\begin{array}{l}2,04 \\
1,79 \\
1,72 \\
1,56\end{array}$ & $\begin{array}{l}- \\
- \\
2,5 \\
-\end{array}$ & $\begin{array}{l}- \\
- \\
0,14 \\
-\end{array}$ & $\begin{array}{l}- \\
- \\
0,28 \\
-\end{array}$ \\
\hline
\end{tabular}

(1) Fes, Fed, Feo = teores de Fe extraídos pelo ataque sulfúrico, pelo ditionito-citrato bicarbonato de sódio e oxalato de amônio, respectivamente.

O perfil P3, originado de sedimentos coluviais pré-edafizados, apresentou aumento noteor deargila em profundidade. Apesar de a relação silte/argila mais elevada nos horizontes superficiais do perfil P3 indicar uma variação na granulometria dos sedimentos, que poderia ser a razão da diferença textural (Moormann, 1985), a análise mineralógica das frações grosseiras não revelou diferenças ao longo do perfil de solo, por provirem os sedimentos da mesma fonte. A estrutura do horizonte Bt mostrou agregados em blocos moderadamente desenvolvidos, formados pela ação dos ciclos alternados de umedecimento e secagem do perfil (Moniz, 1980). Acredita-se que a água, ao percolar, dispersou parte 


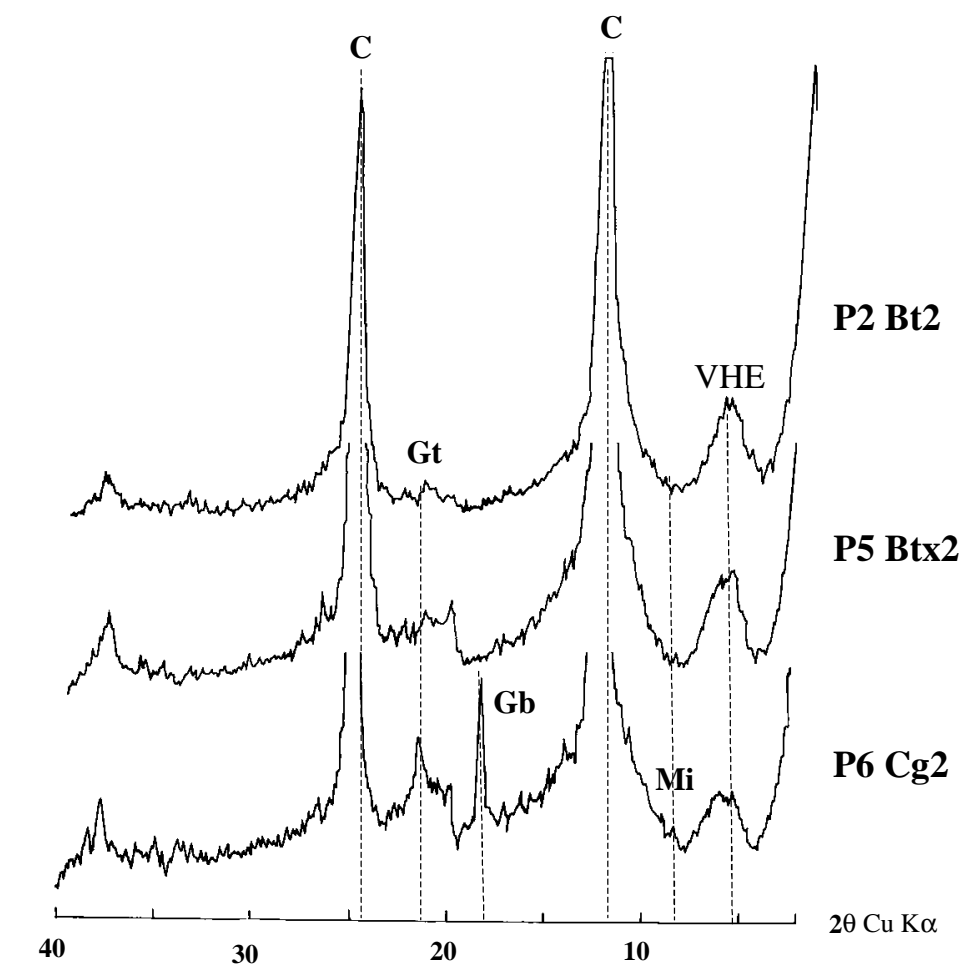

Figura 2. Difratogramas de raios-X da fração argila $\left(\mathrm{K}^{+} 25^{\circ} \mathrm{C}\right)$ dos horizontes diagnósticos dos perfis $\mathrm{P2}$ (Bt2), P5 (Btx2) e P6 (Cg2). VHE =Vermiculita hidróxi-interestratificada; Mi = Mica/ilita; C = Caulinita; Gb = Gibbsita; Gt = Goethita.

das argilas dos horizontes superficiais, favorecendo o mecanismo de perda superficial da argila naturalmente dispersa em suspensão. Desta forma, o processo pedogenético de eluviação/iluviação pouco contribuiu no aumento da relação textural B/A neste perfil.

Também nos perfis $\mathrm{P} 4$ e P5, a relação silte/argila apresentou valores mais elevados nos horizontes superficiais do que em subsuperfície, evidenciando a deposição de sedimentos mais grosseiros, a partir dos quais se originaram os horizontes $\mathrm{A}$ e $\mathrm{E}$, sobre sedimentos mais finos que formaram os horizontes subsuperficiais (Btx). Segundo Duarte et al. (1996), a variação na relação silte/argila pode ser causada ainda por processos de destruição preferencial de argila em superfície e, ou, remoção superficial do material mais fino por escoamento difuso e, ou, iluviação deargila dohorizonteA para oB. A situação dos perfis P4 eP5, em superfície côncava, favorecea infiltração da água no solo, contribuindo para a eluviação de argila dos horizontes superficiais, o que levaria à formação inicial de um horizonte B textural; entretanto, a drenagem imperfeita e a ocorrência sazonal de uma zona saturada na transição entre os horizontes E e B favoreceram a formação do horizonte $B$ plânico pela influência das condições alternadas de oxidação e redução.
A remoção de argilas por erosão sel etiva é suficiente para concentrar o material mais grosseiro na superfície do solo, uma vez que a própria concavidade da superfície reduz a intensidade do arraste das partículas. Desta forma, a variação de granulometria e a formação do horizonte $\mathrm{E}$, nos perfis P4 e P5, deveram-se a diferenças na granulometria dos sedimentos e a processos de destruição de argila nos horizontes superficiais, como o da ferrólise, que pode ter sido acentuado pela presença do fragipã. Segundo Brinkman (1979), a formação do contrastetextural em solos pseudogleis, pseudopodzólicos e planossolos, sujeitos a encharcamento temporário de água, deve-se à destruição das argilas quando a solução do sol o setorna muito ácida, pela al ternância dos processos de redução e oxidação, tornando os argilominerais instáveis.

Dentre os seis perfis estudados, o P6, na planície aluvial, foi o que apresentou menor diferenciação de horizontes, com seqüência de horizontes AC. Sua situação topográfica provocou restrições de drenagem, pelo lençol freático el evado e pelo maior volume deágua que chega ao sol o. O sol o permaneceu úmido durante longo período de tempo, impedindo o desenvolvimento de agregados estruturais nos horizontes Cg. A livre percolação da água, condição indispensável à diferenciação de horizontes, também 


\section{Quadro 4. Mineralogia da fração areia de alguns horizontes dos perfis estudados}

\begin{tabular}{|c|c|c|}
\hline \multirow{2}{*}{ Horizonte } & \multicolumn{2}{|c|}{ Mineralogia dos grãos(1) } \\
\hline & Areia grossa & Areia fina \\
\hline \multicolumn{3}{|c|}{ P5 - Planossolo Háplico } \\
\hline Bt1 & $\begin{array}{l}\text { Quartzo ( } 90 \%) \text {, ang. e subang.; mica al terada (4\%); } \\
\text { fel dspatos ( } 3 \%) ; \text { ilmenita (3\%); zircão e concreções } \\
\text { argilo-ferruginosas (tr) }\end{array}$ & $\begin{array}{l}\text { Quartzo (85\%) ang. e subang.; ilmenita (7\%), mica } \\
\text { alterada (5\%); fel dspato (3\%); zircão, leucoxênio, } \\
\text { apatita e concreções argilo-ferruginosas (tr) }\end{array}$ \\
\hline Bt2 & $\begin{array}{l}\text { Quartzo (84\%), ang. e subang; mica alterada (9\%); } \\
\text { feldspatos (6\%); ilmenita (1\%); concreções argilo- } \\
\text { ferruginosas (tr) }\end{array}$ & $\begin{array}{l}\text { Quartzo (52\%) ang. e subang.; mica alterada (40\%); } \\
\text { ilmenita ( } 5 \%) \text {, fel dspato ( } 3 \%) ; \text { zircão, sericita, } \\
\text { apatita, turmalina, anfibólio e nódulos argilo- } \\
\text { ferruginosos (tr) }\end{array}$ \\
\hline \multicolumn{3}{|c|}{ P1 - Argissolo Vermel ho-Amarelo } \\
\hline Bt1 & $\begin{array}{l}\text { Quartzo (93\%), ang. e subang.; fel dspatos potássico } \\
\text { (5\%); ilmenita ( } 2 \%) \text {; mica alterada e concreções } \\
\text { argilo-ferruginosas (tr) }\end{array}$ & $\begin{array}{l}\text { Quartzo ( } 84 \% \text { ) ang. e subang.; mica ( } 8 \%) \text {, ilmenita } \\
\text { (5\%); feldspato ( } 2 \%) ; \text { nódulos argilo-ferruginosos, } \\
\text { zircão, apatita e sílica amorfa (tr) }\end{array}$ \\
\hline Bt2 & $\begin{array}{l}\text { Quartzo ( } 80 \%) \text {, ang. e subang.; biotita ( } 10 \%) \text {; } \\
\text { fel dspatos ( } 9 \%) ; \text { ilmenita (1\%); concreções argilo- } \\
\text { ferruginosas (tr) }\end{array}$ & $\begin{array}{l}\text { Mica alterada (60\%); quartzo (34\%) ang. e subang.; } \\
\text { feldspato ( } 5 \%) \text {; ilmenita (1\%); zircão, leucoxênio e } \\
\text { nódulos argilo-ferruginosos (tr) }\end{array}$ \\
\hline \multicolumn{3}{|c|}{ P2 - Argissolo Vermel ho-Amarelo } \\
\hline Bt1 & Quartzo (100\%), subang.; biotita e ilmenita (tr). & $\begin{array}{l}\text { Quartzo (98\%) subang.; ilmenita ( } 2 \%) \text {; biotita } \\
\text { alterada, fel dspato, zircão, leucoxênio e sericita (tr). }\end{array}$ \\
\hline Bt2 & Quartzo (100\%), subang.; biotita e ilmenita (tr). & $\begin{array}{l}\text { Quartzo (97\%) subang.; ilmenita (3\%); feldspato } \\
\text { (3\%); zircão, leucoxênio, sillimanita, sericita, mica } \\
\text { alterada e rutilo (tr). }\end{array}$ \\
\hline \multicolumn{3}{|c|}{ P3 - Argissolo Amarelo } \\
\hline Btx1 & $\begin{array}{l}\text { Quartzo ( } 100 \%) \text {, subang.; ilmenita e fel dspato } \\
\text { potássico (tr). }\end{array}$ & $\begin{array}{l}\text { Quartzo (98\%) subang.; mica e fel dspato (3\%), } \\
\text { ilmenita ( } 2 \%) \text {; zircão, mica alterada, leucoxênio, } \\
\text { rutilo, turmalina, silimanita e anfibólio (tr). }\end{array}$ \\
\hline Btx2 & $\begin{array}{l}\text { Quartzo ( } 100 \%) \text {, subang.; ilmenita e fel dspato } \\
\text { potássico (tr). }\end{array}$ & $\begin{array}{l}\text { Quartzo ( } 99 \%) \text { ang. e subang.; mica alterada }(5 \%) \text {; } \\
\text { feldspato ( } 3 \%) \text {, ilmenita (1\%); zircão, leucoxênio, } \\
\text { rutilo e sericita (tr). }\end{array}$ \\
\hline \multicolumn{3}{|c|}{ P4 - Planossolo Háplico } \\
\hline Btx1 & $\begin{array}{l}\text { Quartzo (100\%), subang.; ilmenita e fel dspato } \\
\text { potássico (tr). }\end{array}$ & $\begin{array}{l}\text { Quartzo (99\%), subang.; ilmenita (1\%); zircão, mica } \\
\text { alterada, leucoxênio, rutilo e turmalina (tr). }\end{array}$ \\
\hline Btx2 & $\begin{array}{l}\text { Quartzo ( } 100 \%) \text {, subang.; ilmenita, fel dspato } \\
\text { potássico e bi otita (tr). }\end{array}$ & $\begin{array}{l}\text { Quartzo (99\%), subang.; ilmenita (1\%); zircão, mica } \\
\text { alterada, leucoxênio, rutilo e silimanita (tr). }\end{array}$ \\
\hline \multicolumn{3}{|c|}{ P6 - Gleissolo Háplico } \\
\hline $\mathrm{Cg} 2$ & $\begin{array}{l}\text { Quartzo (100\%), subang.; fel dspato potássico e } \\
\text { carvão (tr). }\end{array}$ & $\begin{array}{l}\text { Quartzo (100\%), subang.; carvão, fel dspato, mica } \\
\text { alterada e ilmenita (tr). }\end{array}$ \\
\hline
\end{tabular}

foi reduzida. O lençol freático el evado e o aporte de matéria orgânica favoreceram a redução do ferro, resultando em cores acinzentadas da matriz do solo que evidenciam o domínio do processo de gl eização.

Os perfis $\mathrm{P} 1$ e $\mathrm{P} 2$ apresentaram cerosidade moderada no horizonte Bt, pouca ou comum, associada à estrutura em blocos, caracterizando o horizonte diagnóstico B textural (EMBRAPA, 1999). Considerando as cores do horizonte $B$ e a atividade da argila, os perfis foram classificados como Argissol os Vermel ho-Amarel os. No perfil P3, não foi observada cerosidade, sendo o horizonte $B$ definido como textural pela relação B/A maior que 1,7, e o solo classificado como Argissolo Amarelo pelo domínio de cores com matiz 10YR. Nos perfis $\mathrm{P} 4 \mathrm{e}$ P5, foi identificada a presença dehorizonte B plânico, pela drenagem imperfeita, horizonte $\mathrm{E}$ sobrejacente, mudança textural abrupta e cor com baixo croma. Observou-se ainda a presença de horizonte fragi pã nestes perfis, identificados pelas cores da matriz do solo e dos mosqueados, consistência dura a muito dura do material quando seco, e quebradicidade dos 
torrões de solo, segundo Franzmeier et al. (1989) e Estados Unidos (1993). Os perfis P4 e P5 foram classificados como Planossolos Háplicos. O perfil P6 revelou horizonte glei definido pelas dominância de cores de redução e foi classificado como Gleissolo Háplico.

\section{CONCLUSÕES}

1. A natureza do material parental ea drenagem dos solos, considerando a posição topográfica e a forma das superfícies, determinaram a atuação de diferentes processos pedogenéticos e a intensidade destes processos na toposseqüência estudada.

2. Nos perfis $\mathrm{P} 1$ eP2, a convexidade da superfície e a posição na encosta favoreceram o mecanismo de translocação e o processo de el uviação/iluviação, formando Argissol os Vermelho-Amarelos. No P3, Argissol oAmarel o originado de sedimentos coluviais, o mecanismo de perda de argila em superfície foi o principal responsável pelo gradiente textural. Nos perfis P4 e P5, a superfície côncava e a drenagem imperfeita contribuíram para o processo de el uviação de argila, que, associado às condições de oxidação e redução e ao processo de ferrólise, levou à formação dePlanossolos Háplicos. O perfil P6, GleissoloHáplico, apresentou o menor grau de diferenciação de horizontes, sendo o principal processo o da gleização.

\section{LITERATURA CITADA}

AMADOR, E.S. Unidades sedimentares cenozóicas do recôncavo da Baía de Guanabara (Fol has Petrópolis e I taboraí). Ann. Acad. Bras. Ci., 52:743-761, 1980.

ANJ OS, L.H.C.; FERNANDES, M.R.; PEREIRA, M.G. \& FRANZMEIER, D.P. Landscape and pedogenesis of an Oxisol-I nceptisol-Ultisol sequence in southeastern Brazil. Soil Sci. Soc. Am. J., 62:1651-1658, 1998.

BIGARELLA, J.J.; MOUSINHO, M.R. \& SILVA, J.X. Considerações a respeito da evolução das vertentes. $B$. Paranaense Geog., 16-17:85-116, 1965.

BRINKMAN, R. Ferrolysis, a soil-forming process in hydromorphic conditions. Pudoc, Wageningen, 1979. 106p. (Agric. Res. Rep., 887)

DEMATTÊ, J.L.I.; VIDAL-TORRADO, P. \& SPAROVEK, G. Influência da drenagem na morfogênese de solos desenvol vidos de rochas básicas no município dePiracicaba (SP). R. Bras. Ci. Solo, 16:241-247, 1992.

DUARTE, M.N.; RAMOS D.P. \& LIMA, P.C. Caracterização e gênese de solos desenvolvidos de cobertura quaternária sobre embasamento cristalino, na baixada litorânea do Estado do Rio deJ aneiro. R. Bras. Ci. Solo, 20:291-304, 1996.

EMPRESA BRASILEIRA DE PESQUISA AGROPECUÁRIA EMBRAPA. Centro Nacional de Pesquisa de Solos. Sistema brasileiro de classificação de solos. Rio de J aneiro, 1999. $412 p$.
EMPRESA BRASILEIRA DE PESQUISA AGROPECUÁRIA EMBRAPA. Serviço Nacional de Levantamento e Conservação do Solo. Manual de métodos de análises do solo. Rio de J aneiro, 1979. não paginado.

EMPRESA BRASILEIRA DE PESQUISA AGROPECUÁRIA EMBRAPA. Serviço Nacional de Levantamento e Conservação do Solo. Levantamento semidetalhado e aptidão agrícola dos solos do município do Rio de J aneiro, RJ . Rio de J aneiro, 1980. 389p. (E mbrapa-SNLCS. Boletim Técnico, 66)

ESTADOS UNIDOS. Soil survey manual. 2.ed. Washington, DC, Soil Survey Staff. USDA-SCS. U.S. Gov. Print. Office, 1993. 437p. (Agricultural Handbook, 18)

ESTADOS UNIDOS. Department of Agriculture. Soil Taxonomy. A Basic System of Classification for Making and Interpreting Soil Surveys. 2.ed. Washington, DC, Soil Survey Staff.USDA-NRCS. U.S. Gov. Print. Office, 1999. 869p. (Agricultural Handbook, 436)

FANNING, D.S. \& FANNING, M.C.B. Soil morphology, genesis and classification. New York, J ohn Wiley \& Sons, 1989. 395p.

FRANZMEIER, D.P.; NORTON, L.D. \& STEINHARDT, G.C. Fragipan formation in loess of the Midwestern United States. In: SOIL SCIENCE SOCIETY OF AMERICA. eds. Fragipans: their ocurrence, classification and genesis. Madison, 1989. p.69-97. (Special Publication, 24)

GOES, M.M.B. Diagnóstico ambiental para geoprocessamento do município de Itaguaí (RJ). Rio Claro, Universidade Estadual Paulista J úlio de Mesquita Filho, 1994. 529p. 2v. (Tese de Doutorado)

J ENNY, H. Factors of soil formation. New York, McGraw-Hill Company, 1941. 281p.

LEONARDOS, O.H. \& FYFE, W.S. Ultrametamorphism and melting of a continental margin in the Rio deJ aneiroregion, Brazil. Contrib. Miner. Petrol., 46:201-214, 1974.

LEMOS, R.C. \& SANTOS, R.D. Manual de descrição e coleta de solos no campo. 2.ed. Campinas, Sociedade Brasileira de Ciência do Solo, 1984. 46p.

MEHRA, O.P. \& J ACKSON, M.L. I ron oxide removal from soil and clays by dithionite-citrate system buffered with sodium bicarbonate. Clays Clay Miner., 5:317-327, 1960.

MONIZ, A.C. Formation of an Oxisol-Ultisol transition in São Paulo, Brazil. Raleigh, North Caroline University, 1980. 290p. (Tese de Doutorado)

MOORMANN, F.R \& BUOL, S.W. The kandic horizon as a diagnostic sub surface horizon. In: MOORMANN, F.R., ed. Expects from the circular letters of the International Committee on Low Activity Clays (ICOMLAC). Washington D.C., Soil Management Support Services, 1985. p.219-227. (SMSS, Technical Monograph, 8)

NASCIMENTO, R.A.M. Correlação entre o valor Ki e outras variáveis em Latossolos. I taguaí, Universidade Federal Rural do Rio de J aneiro, 1989. 256p. (Tese de Mestrado)

RIO DE J ANEIRO. Departamento de Recursos Minerais. Sinópse geológica do estado do Rio de J aneiro: Texto explicativo do mapa geológico 1:40.000. Niterói, Secretaria de Meio Ambiente do Estado do Rio de J aneiro, 1995. 53p. 
SCATOLINI, F.M. \& MONIZ, A.C. Influência do material de origem do lençol freático surgente e da posição topográfica nos sol os de uma encosta em Mococa (SP). R. Bras. Ci. Solo, 16:379-388, 1992.

SCHULZE, D.G. The influence of aluminum on iron oxides. VII. Unit-cell dimensions of Al- substituted goethites and estimation of Al from them. Clays Clay Miner., 32:27-39, 1984.

SCHWERTMANN, $U$. The differentiation of iron oxide in soil by a photochemical extraction with acid ammoniun oxalate. Z. Pflanzenernahr Dung. Bodenkd., 105:104-201, 1964.

SCHWERTMANN, U. \& KÄMPF, N. Óxidos de ferro jovens em ambientes pedogenéticos brasileiros. $\mathrm{R}$. Bras. Ci. Sol o, 7:251255, 1983.
SCHWERTMANN, U. \& TAYLOR, R.M. I ron oxides. In: DIXON, J.B. \& WEED, S.B., eds. Minerals in soil environments. 2.ed. Madison, Soil Science Society of America, 1989. p.379-438.

SILVA, M.B. Caracterização dos solos em uma toposseqüência no campus da UFRRJ . I taguaí, U niversidade Federal Rural do Rio de J aneiro, 1993. 141p. (Tese de Mestrado)

SMITH, B.R. \& CALLAHAN, L.L. Soils with Bx horizons in the upper Coastal Plains of South Carolina. Soil Sci. Soc. Am. J., 51:158-164, 1987.

UEHARA, G. \& GILMAN, G. The mineralogy, chemistry and physics of tropical soils with variable charge clays. Boulder Colorado, Westview Press, 19811. 157p.

VETTORI, L. Ferro "Iivre” por cálculo. In: CONGRESSO BRASILEIRO DE CIÊNCIA DO SOLO, 15., Campinas, 1975. Anais. Campinas, Sociedade Brasileira de Ciência do Solo, 1976. p.127-128. 